DOI 10.5216/ia.v46i3.68320

\title{
COMBATE AO RACISMO PELO “CENTRO DE CULTURA NEGRA - NEGRO COSME" DE IMPERATRIZ (MA)
}

\author{
DOMingos Alves de Almeida \\ Universidade Federal Fluminense (UFF), Niterói, Rio de Janeiro, Brasil \\ IDAYANE DA SILVA FERREIRA \\ Universidade Federal do Maranhão (UFMA), Imperatriz, Maranhão, Brasil \\ MARIA LUÍSA RODRIGUES dE SOUSA \\ Centro de Cultura Negra - Negro Cosme (CCN-NC), Imperatriz, Maranhão, Brasil
}

\begin{abstract}
Resumo: Este trabalho tem como objetivo discutir e analisar o histórico de atuação do "Centro de Cultura Negra - Negro Cosme" (CCN-NC) no combate ao racismo e na promoção de cidadania e direitos humanos em Imperatriz (MA). Para o referencial teórico recorremos a Sousa (2013), Gomes (2012), Munanga (2005), Almeida (2018, 2020) e outros. Adotamos na metodologia a pesquisa bibliográfica, documental e entrevista estruturada. Apontamos a atuação do Centro, empenhada em garantir os direitos humanos e o exercício da cidadania da população negra em Imperatriz (MA). Sua forma de fazer militância social lhe assegura um caráter de movimento negro educador, que busca combater o racismo a partir do interior das estruturas sociais em que o preconceito racial está arraigado.
\end{abstract}

Palavras-chave: Racismo. Direitos Humanos. Cultura Negra. Imperatriz (MA).

\section{INTRODUÇÃO}

O ano de 2020 representa a primeira metade da Década Internacional de Afrodescendentes (2015-2024), proclamada pela Assembleia Geral da Organização das Nações Unidas (ONU) com o tema "Reconhecimento, Justiça e Desenvolvimento", como forma de reconhecer que "os povos afrodescendentes representam um grupo distinto cujos direitos humanos precisam ser promovidos e protegidos" (ONU, 2015). De acordo com este documento, os Estados devem assegurar e promover "o direito à igualdade e à não discriminação, acesso à justiça e direito ao desenvolvimento e medidas contra a pobreza (Educação, Emprego, Saúde e Moradia)".

Este ano, apesar da pandemia provocada pela covid-19, temos um momento histórico significativo para as lutas antirracistas no Brasil e no mundo, por algumas razões que elencaremos. A primeira trata das ações dos movimentos políticos de combate ao racismo que saíram às ruas pautando os debates internacionais, após o assassinato do afro-americano George Floyd, 46 anos, em Mineapolis, Minnesota, nos Estados Unidos no dia 25 de maio. Floyd foi estrangulado por policiais brancos, com um deles ajoelhado em seu pescoço durante uma abordagem em que ele era acusado de, supostamente, usar uma nota falsificada de 20 dólares em um supermercado.

A crueldade do assassinato de George Floyd, mais um dentre centenas de outros praticados por policiais brancos contra negros no país norte-americano, levou de 
volta às ruas o movimento Black Lives Matter - Vidas Negras Importam - repetindo em coro "/ cant breathe" - eu não consigo respirar -, frase repetida mais de 20 vezes por Floyd, enquanto era estrangulado pelo policial branco. As imagens da tortura que circularam nos meios de comunicação uniram negros e brancos aliados em grandes protestos nos Estados Unidos e em dezenas de outros países com histórico de miscigenação racial, como o Brasil.

Enquanto nos Estados Unidos a população afrodescendentes representa 12,3\% do total, no Brasil 56\% da população se autodeclara negra (pretos e pardos), o que faz com que o país tenha o segundo maior contingente populacional negro do planeta (117.910.000), atrás apenas da Nigéria na África (190.886.311). Com histórico de 388 anos de escravidão oficial e apenas 132 anos do fim jurídico do regime escravocrata, o país se torna o principal foco das medidas sugeridas pela ONU para promover a cidadania e garantir os direitos humanos das pessoas negras. Isso se deve às condições sociais de desprivilégio em que se encontra a população negra brasileira e pelos repetidos casos de discriminação racial registrados no país.

Nos primeiros anos do século XXI, o governo brasileiro adotou algumas medidas para atender as demandas do segmento afro-brasileiro, dentre as quais podemos destacar a criação da Secretaria de Políticas de Promoção da Igualdade Racial (Seppir), em 21 de março de 2003, data em que é celebrado o Dia Internacional pela Eliminação da Discriminação Racial, instituído pela Organização das Nações Unidas (ONU) em memória de Massacre de Sharperville (1960). Também a aprovação da Lei 10.639/03, alterada posteriormente pela Lei 11.645/08, que tornou "obrigatório o estudo da História e Cultura Afro-Brasileira e Indígena nos estabelecimentos de ensino fundamental e médio, oficiais e particulares" (BRASIL, 2003); da Lei no 12.288/10 que instituiu o Estatuto da Igualdade Racial; da Lei 12.711/2012, conhecida como Lei das cotas, que determinou a reserva de vagas para pessoas negras nas Instituições Federais de Ensino Superior (IFES) e da Lei de cotas nos Concursos Públicos Federais (Lei 12.990/14).

No Maranhão, em que 76,5\% (IBGE, 2010) da população se auto reconhece negra, o Conselho Estadual de Promoção de Políticas de Igualdade Racial (Ceirma) iniciou, no dia 28 de julho deste ano, o processo de escuta aberta para a construção do Estatuto da Igualdade Racial, com a participação de duas conselheiras-ouvidoras que são militantes do "Centro de Cultura Negra - Negro Cosme" (CCN-NC) de Imperatriz (MA), organização criada em 27 de março de 2002. Desde que o Conselho foi criado em 2007, o Centro participa contribuindo na construção da política racial maranhense, além de participar do Conselho Estadual e Municipal de Segurança Alimentar e do Conselho Municipal da Mulher.

Ao longo desses 18 anos de atuação, o Centro de Cultura Negra tem realizado várias ações concretas em prol da comunidade negra desta que é a segunda maior cidade do Estado do Maranhão. Vale destacar: a criação da Coordenação de Educação da Igualdade Racial de Imperatriz (Ceiri), única do gênero em todo o Estado, para implementação da Lei 10.639/03 nas escolas (SOUSA, 2013); fundação da Companhia Afro de Teatro Reinvent'arte, também a única do Maranhão a tratar da temática negra 
(ALMEIDA, 2018); criação da Editora Balaiada de Escritas Negras para publicar obras produzidas por militantes negros.

Nesse sentido, este trabalho tem como objetivo discutir e analisar o histórico de atuação do Centro no combate ao racismo e na promoção de cidadania e direitos humanos em Imperatriz (MA), bem como verificar as mudanças práticas na sociedade local no que diz respeito aos debates sobre a temática étnico-racial. Como metodologia adotamos a pesquisa bibliográfica, documental e entrevista estruturada com militantes fundadores do movimento negro local. Apontamos a atuação do "Centro de Cultura Negra - Negro Cosme" (CCN-NC) como uma instituição empenhada em garantir os direitos humanos e o exercício da cidadania da população negra em Imperatriz (MA). Sua forma de fazer militância social lhe assegura um caráter de movimento negro educador, que busca combater o racismo a partir do interior das estruturas sociais em que o preconceito racial está arraigado.

\section{NEGRITUDE E RACISMO À BRASILEIRA}

O Brasil foi o último país das Américas a abolir juridicamente a escravidão de negros, em 13 de maio de 1888 (ANDREWS, 2007). Com a sanção da Lei n 3.353/88, conhecida como Lei Áurea, pela então Princesa Isabel, ficou "declarada extincta desde a data desta lei a escravidão no Brazil' (BRASIL, 1888). Era o fim de um processo histórico de 388 anos e o início de outro, pela inserção de negros na sociedade para o exercício pleno da cidadania. A Lei Áurea não assegurou nenhum tipo de amparo ou política pública para garantir direitos aos "libertos" e reparar os atrasos praticados contra eles pelo estado brasileiro. Tampouco demandou aos senhores de escravos qualquer responsabilidade com aqueles agora "cidadãos", em quase sua totalidade, analfabetos, sem ofícios, sem terras para trabalhar, nem dinheiro para iniciar uma vida nova.

Essa falta de reparo aos danos sofridos pelos negros, baixo os ditames da escravidão, são sentidos na atualidade, 132 anos depois. A chegada da pandemia do novo Coronavírus no Brasil deixou ainda mais evidente a situação de vulnerabilidade da população negra, decorrência também do racismo histórico. De acordo com um levantamento de dados epidemiológicos realizado pelo Núcleo de Operações e Inteligência em Saúde da PUC-Rio $(2020)^{1}$, negros são $55 \%$ dos mortos pelo covid-19. Essa situação encontrou o complicador da violência nas comunidades, praticada por criminosos que dominam as áreas e pela polícia, denunciada por familiares de vítimas e organizações de direitos humanos. A gravidade da situação na conjuntura atual levou o Supremo Tribunal Federal (STF) a proibir operações policiais nas comunidades do Rio de Janeiro, atendendo a um pedido do Partido Socialista Brasileiro (PSB) e da Advocacia Geral da União (AGU).

Negros possuem renda menor que brancos, ocupando o mesmo posto e com formação igual, são minorias em cargos de chefia e maioria entre os desempregados. Além disso, compõe a maior taxa de analfabetismo e são a maioria das vítimas de homicídios. Esses fatos levantados pela Pesquisa Nacional por Amostra de Domicílios (PNAD, 2018) revelam o quanto o racismo ainda está arraigado na estrutura da sociedade brasileira (ALMEIDA, 2020), se reproduzindo no cotidiano em um movimento estruturante das relações sociais (GOMES, 2012). A sociedade brasileira continua reproduzindo comportamentos escravocratas e negando direitos à população negra, 
relegando-a à subalternidade. Silvio Almeida (2020) explica que "o racismo azeitado pelas condições econômicas, sociais, políticas e também as condições do imaginário social, que coloca sempre os negros nessa posição, vai destruindo o futuro do Brasil" ${ }^{2 \prime}$.

Cotidianamente assistimos nos meios de comunicação notícias sobre pessoas negras como vítimas das mais variadas facetas do racismo, que estrutura as bases da sociedade brasileira. Dos casos mais recentes podemos destacar os seguintes:

- Polícia mata adolescente João Pedro durante uma operação policial em São Gonçalo, município da Região Metropolitana do Rio de Janeiro (G1 - 18/03/20);

- Universidade de Brasília (UNB) e Universidade de São Paulo (USP) expulsam e cassam diplomas de estudantes por fraudarem o sistema de cotas raciais (G1 13/07/20);

- Entregador é chamado de lixo e é alvo de racismo em SP (Folha - 07/08/20);

- Mãe perde guarda da filha após jovem participar de ritual do candomblé (Geledés - 07/08/20);

- Jovem negro é agredido e ameaçado em shopping no Rio ao tentar trocar relógio (G1 - 07/08/20);

- Bailarino é alvo de racismo por black power e recebe apoio de famosos (Uol 07/08/20);

- Noiva pede que cantora alise cabelo para "ficar melhor nas fotos" (Geledés 30/07/20).

Esses casos elencados são apenas uma amostra dos que viraram notícias na mídia, dentre os vários que ocorreram no país, muitos deles sem qualquer repercussão na esfera pública. E todas as vítimas possuem uma característica em comum, o marcador sociorracial que as tornam alvos da discriminação: a cor da pele. $O$ caso da expulsão dos estudantes que fraudaram o sistema de cotas na Universidade de Brasília (UNB) e na Universidade de São Paulo (USP) é sintomático do racismo estrutural da nossa sociedade, manifestado na negação histórica de direitos aos negros brasileiros. Destacamos esse caso por entendermos que nele está materializado o movimento racista em que pessoas brancas continuam obstaculizando as possibilidades de imersão das pessoas negras.

Esses casos de discriminação acontecem à revelia de uma legislação que criminaliza e determina punições aos atos de racismo. O Inciso XLII do Artigo $5^{\circ}$ da Constituição Federal determina que "a prática do racismo constitui crime inafiançável e imprescritível, sujeito à pena de reclusão, nos termos da lei" (BRASIL, 2016, p. 15). A Lei $7.716 / 89$ define os crimes resultantes de preconceito de raça ou de cor e regulamenta as respectivas punições. Além do artigo 140 , parágrafo $3^{\circ}$, do Código Penal, que trata dos crimes de injúria racial. Mesmo com todos esses mecanismos de proteção jurídica aos negros, os racistas continuam se manifestando. E, mais recentemente, podemos afirmar que eles vêm se sentido legitimados e autorizados por discursos oficiais de autoridades.

Nesse sentido, Munanga (2005) e Almeida (2018) chamam a atenção para o fato de que as leis antirracistas são importantes, mas não suficientes para solucionar o problema da discriminação racial, entendida como uma prática que vai além de atitudes 
ALMEIDA, D. A. de; FERREIRA, I. da S.; SOUSA, M. L. R. de.

pontuais dos sujeitos racistas. "Ainda que os indivíduos que cometam atos racistas sejam responsabilizados, o olhar estrutural sobre as relações raciais nos leva a concluir que a responsabilização jurídica não é suficiente para que a sociedade deixe de ser uma máquina produtora de desigualdade racial" (ALMEIDA, 2018, p. 39). Munanga (2005) defende que a legislação punitivista precisa vir acompanhada de um processo educacional para desconstruir a mentalidade supremacista que cimenta a prática discriminatória contra negros.

Não existem leis no mundo que sejam capazes de erradicar as atitudes preconceituosas existentes nas cabeças das pessoas, atitudes essas provenientes dos sistemas culturais de todas as sociedades humanas. No entanto, cremos que a educação é capaz de oferecer tanto aos jovens como aos adultos a possibilidade de questionar e desconstruir os mitos de superioridade e inferioridade entre grupos humanos que foram introjetados neles pela cultura racista na qual foram socializados (MUNANGA, 2005, p. 17).

Assim, de acordo com Sílvio Almeida (2018), o combate à discriminação racial necessita um olhar mais profundo para a estrutura da sociedade brasileira e não somente para os sujeitos racistas isoladamente. Para ele, "as expressões do racismo no cotidiano, seja nas relações interpessoais, seja na dinâmica das instituições, são manifestações de algo mais profundo, que se desenvolve nas entranhas políticas e econômicas da sociedade" (ALMEIDA, 2018, p. 16). Gomes (2012) acrescenta afirmando que "o racismo brasileiro opera não somente na estrutura do Estado, mas também na vida cotidiana das suas próprias vítimas" (p. 731), e considera imprescindível "essa interpretação da raça como estrutural e estruturante para se compreender a complexidade do quadro de discriminação e desigualdades no Brasil" (GOMES, 2012, p. 734, grifo nosso). A partir disso, Almeida (2018, p. 25) reforça que o racismo é, antes de tudo, "estrutural" e conceitua-o como "uma forma sistemática de discriminação que tem a raça como fundamento, e que se manifesta por meio das práticas conscientes ou inconscientes que culminam em desvantagem ou privilégios para indivíduos, a depender do grupo social ao qual pertençam".

A história oficial reproduz arquétipos que menospreza, inferioriza e discrimina a contribuição dos negros brasileiros para construção do país. Kabengele Munanga (2005) explica que isso se deve a uma educação eurocêntrica em que a história é "apresentada apenas do ponto de vista do 'Outro' e seguindo uma ótica humilhante e pouco humana" (MUNANGA, 2005, p. 16). Nesse aspecto, o movimento negro articula suas práticas para ressignificar essa abordagem histórica de apagamento e negação, e "[...] ao agir social e politicamente, reconstrói identidades, traz indagações, ressignifica e politiza conceitos sobre si mesmo e sobre a realidade social (GOMES, 2012, p. 735).

Pela envergadura do racismo estrutural no Brasil, os autores aqui elencados são unânimes em enfatizar que é necessário o envolvimento de toda a sociedade na luta contra a discriminação racial. Almeida (2020) é enfático em pontuar que é imprescindível que os brancos aliados "se engajem na luta antirracista, porque, sem que os brancos participem diretamente, o que os negros podem fazer é apenas resistir dentro de um processo e nunca avançar em direção de o derrotar" (ALMEIDA, 2020). Esse engajamento é necessário porque ainda segundo o ator, "sem os brancos não é possível superar o 
racismo, justamente porque os brancos também são uma criação do racismo" (ALMEIDA, 2020).

Essa é exatamente a forma de atuar do "Centro de Cultura Negra - Negro Cosme" (CCN-NC) de Imperatriz (MA.) Desde os primeiros debates do movimento negro local, ainda na década de 1990, que é adotado o entendimento da importância da participação de brancos na luta antirracista, por considerar que, assim como os negros padecem dos males da estrutura racista, os brancos usufruem, de forma consciente e inconsciente, dos privilégios legados do sistema escravocrata. É necessária a união para garantir a cidadania e promover os direitos humanos fundamentais da pessoa negra.

\title{
CCN - NEGRO COSME, CIDADANIA, DIREITOS HUMANOS E O MOVIMENTO NEGRO EDUCADOR
}

O movimento negro é entendido como a principal instituição educadora da sociedade brasileira para o debate acerca das relações étnico-raciais. Ao agir, o movimento provoca fissuras na estrutura racista dominante, abrindo espaços para realizar mudanças concretas na sociedade. "Ao trazer o debate sobre o racismo para a cena pública e indagar as políticas públicas e seu compromisso com a superação das desigualdades raciais, este movimento social ressignifica e politiza a raça, dando-lhe um trato emancipatório e não inferiorizante" (GOMES, 2012, p. 733). Desse modo, não é de se estranhar que a criação do "Centro de Cultura Negra - Negro Cosme" (CCN-NC) esteve, desde o seu início, atrelada à educação.

As discussões sobre a temática negra já se davam desde os anos 80 , no entanto, foi a partir de um pequeno grupo de professoras, professores, estudantes universitários e outros cidadãos que a organização do movimento em Imperatriz (MA) começou a ganhar corpo já na década de 1990. Segundo Sousa (2013, p. 34), o grupo passou a se reunir no pátio do então Centro de Estudos Superiores de Imperatriz (Cesi) da Universidade Estadual do Maranhão - UEMA, atual Universidade Estadual da Região Tocantina do Maranhão (Uemasul), para debater "ações a serem desenvolvidas na busca de incluir a temática afro nas discussões em sala de aula e no ambiente escolar onde trabalhavam". Com as primeiras reuniões vieram também as críticas e censuras aos militantes.

\begin{abstract}
Nessas reuniões realizavam análises e reflexões acerca do 13 de maio e do 20 de novembro, datas alusivas ao movimento negro. Tais atividades aconteciam no pátio da Universidade Estadual do Maranhão - UEMA, Centro de Estudos Superiores de Imperatriz CESI, onde ocorria às reuniões de estudo semanais, planejamento para estender o movimento a outros setores da cidade. Convém ressaltar, que nos primeiros anos, esse trabalho foi muito difícil, porque a maioria das pessoas, mesmo da universidade, entendiam que tal movimento poderia provocar uma revolta dos negros contra os brancos ou o racismo às avessas; censuravam os militantes de complexos de inferioridade, por isso criticavam essa iniciativa. Daí então, é que surgiram os primeiros passos para a criação do Centro de Cultura Negra, Negro Cosme - CCNNC (SOUSA, 2013, p. 34).
\end{abstract}


ALMEIDA, D. A. de; FERREIRA, I. da S.; SOUSA, M. L. R. de.

Conforme sinaliza Sousa (2013), o grupo era composto inicialmente por Izaura Silva (professora da então Universidade Estadual do Maranhão - Uema), Maria Luísa Rodrigues de Sousa (professora da rede municipal), Luiz Maia da Silva (acadêmico de História da Uema), Antonio Lima Ferreira (acadêmico de Letras da Uema), Luiz Carlos Santos Rodrigues (professor da UEMA e engenheiro elétrico da Eletronorte) e outros colaboradores. Somou-se a esse movimento, posteriormente, Mariano Dias (vereador pelo Partido dos Trabalhadores), Jorge Diniz de Oliveira, Maria Conceição Ferreira Pereira Diniz, Francisco das Chagas Matos, Herli de Sousa Carvalho, Lázaro Alves Ferreira, Maria das Neves Gomes Pereira, Maria Erotilde Nunes Leite, Valter Rocha de Andrade e outros (SOUSA, 2013).

As discussões na Uema resultaram na instituição do 20 de novembro como Dia Municipal da Consciência Negra, em Imperatriz (MA), através da Lei Municipal № 973, de 11 de junho de 2001, de autoria do na época vereador Mariano Dias (PT), que se tornou o primeiro presidente do Centro de Cultura Negra (2002-2004). Assim, em novembro de 2001 foi realizada a primeira versão da Semana Municipal da Consciência Negra na cidade, desde então já foram realizadas 17 Semanas Municipais da Consciência Negra e 2 Novembros Negro (esse último incorporou a Semana), organizados pelo Centro em parceria com diversas faculdades, universidades e institutos superiores, escolas municipais e estaduais e sociedade em geral de cidades do Maranhão e Tocantins, com um calendário de atividades culturais (SOUSA, 2013).

A Semana Municipal da Consciência Negra, também se configurava
como espaço de divulgação e tentativa de contribuir para a
conscientização da população negra e não negra. Houveram
diversos momentos importantes em que eram realizadas
entrevistas na imprensa, além de palestras nas escolas públicas e
privadas as quais se tornaram sensíveis à causa (SOUSA, 2013, p. 36).

Herli de Sousa Carvalho, professora universitária e uma das fundadoras do Centro, aponta que entre as maiores dificuldades encontradas no início da organização do movimento negro em Imperatriz estava a falta de um espaço físico para a realização das reuniões. Embora, segundo ela, tenha havido a generosidade de pessoas físicas e jurídicas, tais como o Centro de Cultura Negra do Maranhão (Magno Cruz, Carlos Bendito, Luís Alves, Mundinha Araújo), Academia Imperatrizense de Letras, universidades e Faculdades (Uema - Uemasul, UFMA, FEST, Unisulma), Ordem dos Advogados do Brasil OAB - MA, Sindicato dos Trabalhadores em Estabelecimentos em Ensino de Imperatriz (STEEI), Centro de Ensino Dorgival Pinheiro de Sousa e Unidade Regional de Educação de Imperatriz (Urei). Carvalho (informação verbal) explica que:

\footnotetext{
Contamos com a ajuda de muitxs militantes e simpatizantes que se disponibilizaram ao longo dos 20 anos em se manifestarem das mais diversas formas. Portanto, a ausência/saída de algumas dessas pessoas atuantes de certa maneira foi também uma dificuldade pelo fato de ter que juntar ao coletivo, contando com o esforço de poucas pessoas, tantas formas de pensar, agir, fazer do movimento negro (CARVALHO, 20203).
}

Inter-Ação, Goiânia, v.46, n.3, p. 1460-1474, set./dez. 2021. Disponível em: <http://dx.doi.org/10.5216/ia.v46i3.68320>. 
Para além do debate coletivo, o movimento negro em Imperatriz percebeu a necessidade da criação de uma instituição que afirmasse o movimento enquanto entidade, os militantes sentiam o desejo "de obter uma instituição jurídica na sociedade que os representassem enquanto etnia e para ter respaldo de combater o racismo, o preconceito e a discriminação em nossa sociedade" (SOUSA, 2013, p. 35). Assim, em 27 de março de 2002 foi fundado o "Centro de Cultura Negra - Negro Cosme", em uma assembleia geral ocorrida na Academia Imperatrizense de Letras (AIL), com a aprovação do Estatuto e a realização da primeira eleição da Diretoria, era a concretização institucional para a promoção da consciência e cidadania negras, e pela construção de uma sociedade sem discriminação racial.

[...] com a certeza de que estava nascendo em Imperatriz uma alternativa nova para as camadas mais excluídas, seja nas escolas, ou em outros espaços sociais. Esse acontecimento ímpar ocorreu com a presença de seus membros, políticos, representantes de associações, movimentos sociais, entidades de classe, pastorais, e os representantes do CCN-MA Magno Cruz e Benedita Freire (SOUSA, 2013, p. 35).

Desde sua criação, o CCN-NC tem contribuindo para a implementação, à época, da Lei 10.639/03, atual Lei 11.645/08 - da obrigatoriedade do Ensino de História e Cultura Afro-Brasileira, Africana e Indígena -, na rede estadual de ensino de Imperatriz com "oficinas de formação continuada com professores, coordenadores e gestores, além de minicursos e oficinas com professores, e palestras para alunos da rede estadual, para instituições de ensino superior e também empresas privadas" (SOUSA, 2013, p. 36), atividades culturais e de mobilização.

Em outubro de 2007, o Centro de Cultura Negra conseguiu, junto à Secretaria de Estado da Educação (Seduc-MA), a criação da Coordenação de Educação da Igualdade Racial de Imperatriz (Ceiri), que faz parte da Seduc e da Unidade Regional de Educação de Imperatriz (UREI) e seu objetivo é a implementação da Lei № 11.645/08 nas escolas da rede estadual de ensino, tanto de Imperatriz quanto dos demais municípios da Unidade. Além da Ceiri, o Centro também incentivou a criação da Coordenação de Inclusão do Município de Imperatriz, deste modo podemos observar que o CCN-NC tem motivado o governo a criar órgãos implementadores da Lei № 11.645/2008.

Nesse sentido, retomamos o pensamento de Gomes (2012) que reforça o papel da educação para a garantia do exercício da cidadania de pessoas negras e destaca a atuação do movimento negro do país, como a Frente Negra Brasileira (FNB), Movimento Negro Unificado (MNU) e demais grupos e coletivos negros em atuação na atualidade, para a garantia do acesso a uma educação emancipatória desse grupo racial excluído. Segundo ela, esse "movimento social, por meio de suas ações políticas, sobretudo em prol da educação, reeduca a si próprio, o Estado, a sociedade e o campo educacional sobre as relações étnico-raciais no Brasil, caminhando rumo à emancipação social" (GOMES, 2012, p. 727).

No decorrer de sua trajetória, o CCN-NC se tornou uma referência para pesquisadores e comunidade, além de disponibilizar um acervo bibliográfico para 
professores e alunos, participa ativamente de congressos, encontros e conferências de nível regional, estadual e nacional, como o Congresso Brasileiro de Pesquisadores Negros (Copene) e de conselhos sobre a temática negra, tais como o Conselho Estadual de Promoção da Igualdade Racial (Ceirma), Conselho Estadual e Municipal de Segurança Alimentar e do Conselho Municipal da Mulher.

Outro ponto de atuação do Centro é no desenvolvimento de atividades culturais de valorização da negritude, como festas temáticas, desfiles, apresentações de grupos folclóricos tradicionais, festivais de música negra, teatro, interpretação de literatura negra com participação de alunos das redes estadual e municipal. Anualmente realiza em parceria com a Ceiri um concurso de desenhos afro que envolve estudantes do estado e do município e ocorre no Salão do Livro de Imperatriz (Salimp). Como resultado da promoção de atividades culturais, foi criada no ano de 2013, em parceria com o Centro de Ensino Urbano Rocha, a Companhia Afro de Teatro Reinvent'arte, incumbida de montar espetáculos com a temática negra (ALMEIDA, 2018). Mais recentemente, em 2020, foi criado a Editora Balaiada de Escritas Negras para publicar obras produzidas por militantes negros.

Ao longo de sua atuação, o Centro de Cultura Negra - Negro Cosme (CCN-NC) tem realizado uma série de ações concretas para o debate da questão negra nos mais diferentes espaços: escolas, empresas privadas, espaços culturais, conselhos, comissões etc. Além de buscar atuar junto a organismos públicos que representam os interesses da coletividade, como o Ministério Público, e de se posicionar publicamente diante de casos de racismo e de retrocesso aos direitos adquiridos pela população. Elencamos a seguir algumas das articulações e ações realizadas pelo CCN-NC: integra a Comissão de validação das cotas na Universidade Federal do Maranhão (UFMA) - Campus Imperatriz desde 2010, um ano antes do Ministério da Educação (MEC) universalizar as Ações Afirmativas nas Instituições de Ensino Superior no País; é membro de conselhos estaduais e municipais: Conselho Estadual da Igualdade Racial (Ceirma), Conselho Estadual de Segurança Alimentar, Conselho Municipal de Segurança Alimentar, Conselho Municipal da Mulher.

Em 2018, após a divulgação de editais para seleção de turmas de mestrados de três Programas de Pós-Graduação da UFMA de Imperatriz, em que não constavam vagas destinadas para ações afirmativas, o Centro de Cultura Negra notificou a Pró-Reitoria de Pesquisa, Pós-Graduação e Inovação (PRPPGI), a Direção da Universidade e as coordenações dos Programas, requerendo a inclusão das cotas no processo seletivo. $\mathrm{O}$ Programa de Pós-Graduação em Formação Docente em Práticas Educativas (PPGFOPRED) - Mestrado Profissional em Educação foi o único que não atendeu a reivindicação e, com isso, o CCN solicitou providências junto ao Ministério Público Federal (MPF) para que mediasse a situação. Como resultado a Coordenação do programa assumiu o compromisso de estabelecer o sistema de cotas a partir das seleções seguintes.

Em 2019, após um professor africano ser vítima de racismo em sala de aula na Universidade Estadual da Região Tocantina do Maranhão (Uemasul), o Centro divulgou nota cobrando responsabilidades da instituição. Após a divulgação do documento a Universidade se posicionou publicamente sobre o caso e chamou o CCN-NC para consulta sobre as medidas a serem adotadas contra a estudante racista. Mais recentemente a entidade criticou, também por meio de nota, o cancelamento da 
portaria do Ministério da Educação (MEC) que regulamentava a adoção de cotas na Pósgraduação.

Conforme notamos, o "Centro de Cultura Negra - Negro Cosme" atua em distintas frentes no sentido de garantir que a temática étnico-racial seja discutida, mas, sobretudo, que os negros sejam sujeitos propositivos de políticas públicas de combate ao racismo estrutural. Para isso, além de participar dos espaços públicos de debate propondo medidas, realiza monitoramento e contribui para a implementação de políticas sociais como foco aos grupos raciais. Nesse sentido Carvalho (informação verbal, 2020) afirma que o Centro tem representado um espaço de avanços da luta negra em Imperatriz e no Maranhão, assim como para a visibilidade da causa:

\begin{abstract}
Representa um espaço de luta pela visibilidade da causa negra na Região; espaço de formação continuada de docentes e pessoas interessadas pela temática; espaço de representação do povo negro em vários Conselhos municipais e estaduais; espaço de realização de estudos (cursos, oficinas...), pesquisas (sujeito $X$ objeto) e, extensão (palestras, concursos...) nas instituições municipais, estaduais, particulares e federais; espaço de participação em comissões de validação de cotas para negrxs; espaço de empoderamento de tantas pessoas que se constituem em identidades étnico-raciais; espaço de conhecimento da academia, de envolvimento com Comunidades Quilombolas, Povos Indígenas, Movimentos Sociais, Povos de Matriz Africana; espaço de partilha de lutas diárias com foco no exemplo significativo de Negro Cosme "Imperador da Liberdade" de ser negrx com orgulho e pertencimento (CARVALHO, 20204).
\end{abstract}

Para além das lutas antirracistas, o movimento negro também se constitui como uma instituição solidária e de acolhimento, sendo o principal mediador entre a população negra e as instituições políticas responsáveis por garantir a dignidade desse grupo excluído historicamente. No contexto da pandemia provocada pelo novo coronavírus, que assola o país e castiga mais fortemente as comunidades das periferias, e diante das constantes violências sofridas, Almeida (2020) ressalta que "o movimento negro é agora a solidariedade que existe dentro das favelas para proteger as pessoas". Essa crise sanitária deixou ainda mais evidente a estrutura racista da sociedade brasileira, em que os negros são os mais vulneráveis à contaminação e à morte pela covid-19.

\title{
CONCLUSÕES
}

Ao longo de quase 20 anos de atuação do "Centro de Cultura Negra - Negro Cosme (CCN-NC)" em Imperatriz foram ampliadas as conquistas da população negra, tanto por uma efetiva presença da instituição nos diversos setores da sociedade imperatrizense quanto pelo engajamento em lutas nacionais junto a outros movimentos sociais. O crescimento em 83\% da população preta local, entre 2000 e 2010 (IBGE, 2010), coincide exatamente com o período de atividades efetivas da instituição no esclarecimento sobre a questão étnico-racial. Entretanto, mesmo com todos os avanços 
já elencados ao longo deste trabalho, entendemos que os desafios pela igualdade racial ainda exigem muitos esforços porque se apresentam cotidianamente nas diversas instâncias da sociedade brasileira.

E os avanços são urgentes na educação, área que consideramos elementar para transformar a mentalidade racista. De acordo com os dados do Atlas Brasil (2013), em Imperatriz os negros continuam com déficit educacional em relação aos brancos. A taxa de analfabetismo da população negra de 18 anos ou mais é de quase $12 \%(11,88 \%)$, enquanto que a de branco é menos de $8 \%$ (7,85\%). E quanto maior é o grau de escolaridade, menor é o percentual de negros no grupo. A partir de dados como esse entendemos a relevância das estratégias de atuação do Centro no campo educacional junto a escolas, faculdades, institutos e universidades, públicos e privados. Além da construção de diálogos com diversas outras instituições e com o poder público no sentido de assegurar a efetivação de direitos conquistados.

Em tempos em que está cada vez mais difícil realizar mobilizações nas ruas, espaço perdido nos últimos anos pelas militâncias sociais de diversas naturezas, e com multiplicação de manifestação em redes sociais através de notas de repúdio e outros instrumentos, o CCN-NC consolida sua prática assertiva de fazer sua militância de forma mais presente no dia a dia da comunidade em que atua. Cabe ressaltar que a instituição está presente no ambiente virtual, por meio de seus canais oficiais de comunicação (Blog, Facebook e Instagram), e tem feito uso de plataformas digitais para realizar atividades no contexto da Pandemia provocada pelo novo coronavírus, seguindo as recomendações das autoridades sanitárias para evitar aglomerações. Assim como tem feito notas e outros documentos para circular nesse universo comunicacional.

No entanto, levando em conta o histórico de suas práticas, notamos que essas estratégias de militância virtualizada não são suficientes, no contexto imperatrizense, pois o Estado do Maranhão tem o maior índice de casas sem internet do país (IBGE, 2017). Outro ponto a se destacar é o fato de o Centro não chamar manifestações para as ruas, apesar de participar de todas as que considera importantes para as lutas sociais, se integrando a outras organizações e instituições. A partir disso, consideramos que a luta negra empreendida pela instituição e seus militantes busca se inserir no interior de estruturas, principalmente educativas, e promover as mudanças de dentro para fora. Estratégia que tem surtido efeitos concretos, conforme já apontamos.

Para alcançar esses resultados o "Centro de Cultura Negra - Negro Cosme" (CCN-CN) está constantemente pautando ações concretas em Imperatriz, realizando atividades e ocupando espaço nos meios de comunicação, garantindo, assim, maior visibilidade à temática racial. Com essa atuação, o movimento negro direcionado pelo CCN proporcionou aos negros imperatrizenses conquistas concretas irreversíveis em muitos aspectos, dentre os quais podemos destacar o aumento no número de pessoas que se reconhecem como negras e a própria consolidação de sua existência no imaginário social. Por sua inserção na sociedade local, promovendo os direitos humanos e garantindo o exercício da cidadania da pessoa negra, o Centro já foi tema de diversos trabalhos acadêmicos, em distintas áreas do conhecimento.

Diante disso podemos afirmar, à luz do que nos dizem os autores recorridos para este escrito, que a atuação do Centro busca combater o racismo a partir do interior da estrutura e proporcionar uma ressignificação do ser negro na sociedade, ao mesmo tempo que enfrenta o preconceito racial a partir de instrumentos legais instituídos. Ao 
fincar sua relação com instituições educativas oficiais e mediar a relação dessas com a comunidade negra, consolida sua importância na construção de uma sociedade mais igualitária, contribuindo para a valorização da identidade negra, historicamente negligenciada, além de se firmar com um "movimento negro educador".

Artigo recebido em: $24 / 03 / 2021$

Aprovado para publicação em: 03/11/2021

COMBATING RACISM BY AT THE "CENTER FOR BLACK CULTURE - NEGRO COSME", IMPERATRIZ (MA)

ABSTRACT: This work aims to discuss and analyze the history of the Center for Black Culture Negro Cosme (CCN-NC) in the fight against racism and in the promotion of citizenship and human rights in Imperatriz - MA. For the theoretical framework we used Sousa (2013), Gomes (2012), Munanga (2005), Almeida (2018-2020) and others. We adopted in the methodology the bibliographic research, documentary and structured interview. We point to the action of the Center committed to guaranteeing human rights and the exercise of citizenship of the black population in Imperatriz - MA. And that, his way of doing social militancy assures him a character of black movement educator that seeks to combat racism from within social structures where racial prejudice is entrenched.

KEYWORDS: Racism. Human Rights. Black Culture. Imperatriz - MA.

COMBATE AL RACISMO POR EN EL "CENTRO DE CULTURA NEGRA - NEGRO COSME" DE IMPERATRIZ (MA)

RESUMEN: Este trabajo tiene como objetivo debatir y analizar la historia del Centro de Cultura Negra - Negro Cosme (CCN-NC) en la lucha contra el racismo y en la promoción de ciudadanía y derechos humanos em Imperatriz - MA. Para el marco teórico utilizamos Sousa (2013), Gomes (2012), Munanga (2005), Almeida (2018-2020) y otros. Adoptamos en la metodología la investigación bibliográfica, documental y entrevista estructurada. Señalamos para la actuación del Centro comprometida con la garantía de los derechos humanos y el ejercicio de la ciudadanía de la población negra en Imperatriz - MA. Y que su forma de hacer militancia social le asegura un carácter de movimiento negro educador que busca combatir el racismo desde dentro de las estructuras sociales donde los prejuicios raciales están arraigados.

PALABRAS CLAVE: Racismo. Derechos Humanos. Cultura Negra. Imperatriz - MA. 


\section{NOTAS}

1 - Disponível em: https://www.bbc.com/portuguese/brasil-53338421. Acesso em: 08 jul. 2020

2 - Disponível em: https://www.youtube.com/watch?v=L15AkiNmOlw. Acesso em: 10 jul. 2020.

3 - Entrevista concedida por Carvalho, H. S. aos autores em 15 jul. 2020.

4 - Entrevista concedida por Carvalho, H. S. aos autores em 15 jul. 2020.

\section{REFERÊNCIAS}

ALMEIDA, D. A. Quando o teatro ocupa a escola para denegrir: o caso da primeira Companhia Afro de Teatro estudantil de Imperatriz - MA. Revista Capim Dourado: Diálogos em Extensão, Palmas, v. 1, n. 2, 2018.

ALMEIDA, S. O que é racismo estrutural? Belo Horizonte: Letramento, 2018.

ANDREWS, G. R. América Afro-Latina: 1800-2000. Trad.: Magda Lopes. São Carlos: EdUFSCar, 2007.

BRASIL. [Constituição (1988)] Constituição da República Federativa do Brasil: texto constitucional promulgado em 5 de outubro de 1988, com as alterações determinadas pelas Emendas Constitucionais de Revisão nos 1 a 6/94, pelas Emendas Constitucionais nos 1/92 a 91/2016 e pelo Decreto Legislativo no 186/2008. Brasília: Senado Federal, Coordenação de Edições Técnicas, 2016.

BRASIL. [Lei Áurea]. Lei no 3.353 de maio de 1888: Declara extinta a escravidão no Brasil. Disponível em: http://www.planalto.gov.br/ccivil_03/leis/lim/LIM3353.htm. Acesso em: 10 jul. 2020.

BRASIL. Lei no 11.645, de 10 março de 2008: Altera a Lei no 9.394, de 20 de dezembro de 1996, modificada pela Lei no 10.639, de 9 de janeiro de 2003, que estabelece as diretrizes e bases da educação nacional, para incluir no currículo oficial da rede de ensino a obrigatoriedade da temática "História e Cultura Afro-Brasileira e Indígena". Disponível em: http://www.planalto.gov.br/ccivil_03/_Ato2007-

2010/2008/Lei/L11645.htm. Acesso em: 08 jul. 2020.

CARVALHO, H. S. Entrevista concedida aos autores. Imperatriz - MA, 2020.

GOMES, N. L. Movimento negro e educação: ressignificando e politizando a raça. Educ. Soc., Campinas, v. 33, n. 120, 2012.

IBGE. Instituto Brasileiro de Geografia e Estatística. Censo Demográfico 2010. População por Cor - 1991-2000-2010. Imperatriz - MA, 2010. 
IBGE. Pesquisa Nacional por Amostra de Domicílios Contínua - PNAD. Desigualdades Sociais por Cor ou Raça no Brasil. Estudos e Pesquisas: Informação Demográfica e Socioeconômica, n.41, IBGE: Rio de Janeiro, 2019.

ONU. 2015-2024: Década Internacional de Afrodescendentes, c2015. Página inicial. Disponível em: http://www.decada-afro-onu.org/. Acesso em: 07 jul. 2020.

PERFIL. Atlas do Desenvolvimento Humano no Brasil. Imperatriz - MA. Disponível em: http://atlasbrasil.org.br/2013/pt/perfil_m/imperatriz_ma. Acesso em: 16 jul. 2020.

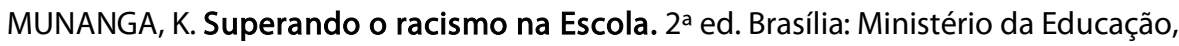
Secretaria de Educação Continuada, Alfabetização e Diversidade, 2005.

SOUSA, M. L. R. A contribuição do Centro de Cultura Negra Negro Cosme na implementação da Lei № 10.639/2003 nas escolas estaduais em Imperatriz - MA. Monografia apresentada ao Curso de Especialização em Gestão de Políticas Públicas em Gênero Raça da Universidade Federal do Maranhão (UFMA), Imperatriz, 2013.

Domingos Alves de Almeida: Doutorando do Programa de Pós-Graduação em Mídia e Cotidiano pelo Instituto de Arte e Comunicação Social - IACS II, da Universidade Federal Fluminense - UFF. Mestre em Integração Contemporânea da América Latina ICAL e Especialista em Relações Internacionais Contemporâneas - RIC, ambos pelo Instituto Latino-Americano de Economia, Sociedade e Política - ILAESP, da Universidade Federal da Integração Latino-Americana - UNILA. Graduado em Comunicação Social com Habilitação em Jornalismo pela Universidade Federal do Maranhão (UFMA), Campus de Imperatriz.

Orcid: https://orcid.org/0000-0002-1857-8201

E-mail: domingosaa@id.uff.br

Idayane da Silva Ferreira: Mestranda em Comunicação pelo Programa de PósGraduação em Comunicação (PPGCOM) da Universidade Federal do Maranhão (UFMA). Especialista em Assessoria de Comunicação Empresarial e Institucional pela UFMA. Graduada em Comunicação Social com habilitação em Jornalismo pela UFMA.

Orcid: https://orcid.org/ 0000-0002-0532-9644

E-mail: idayaneferreira@gmail.com

MARIA LuísA Rodrigues de Sousa: Possui graduação em Licenciatura Plena em Letras pela Universidade Estadual do Tocantins. Atualmente é professora da Secretaria de Educação do Estado do Tocantins e na Secretaria de Educação do Estado do Maranhão estando na Coordenação de Educação da lgualdade Racial - CEIRI. Militante e fundadora do Centro de Cultura Negra Negro Cosme em Imperatriz - MA. Tem experiência na área de Educação, com ênfase em História e Cultura Afro Brasileira e Africana. 
ALMEIDA, D. A. de; FERREIRA, I. da S.; SOUSA, M. L. R. de.

Orcid: https://orcid.org/0000-0002-2187-0238

E-mail:marilusol@hotmail.com

Este periódico utiliza a licença Creative Commons Attribution 3.0, para periódicos de acesso aberto (Open Archives Initiative - OAI).

Inter-Ação, Goiânia, v.46, n.3, p. 1460-1474, set./dez. 2021. Disponível em: <http://dx.doi.org/10.5216/ia.v46i3.68320>. 